Lectures in Medical Genetics are a series given to the faculty and students of the Northwestern University Medical School at Chicago. Dr. Hsia and nine of his colleagues cover a very wide field in the twelve lectures recorded here. Six of these are devoted to clinical aspects: mendelian genetics, genetics problems (such as mutation, linkage, multifactorial inheritance, and nonnuclear inheritance), and population genetics being dealt with by $H$. M. Slatis, while the Editor himself deals with molecular disturbances, enzyme defects, and the place of genetics in clinical practice. The theoretical aspects of present-day human genetics are covered by the two opening sections of this book, morphological genetics being discussed in chapters on the structure of the cell, the life cycle of the cell and chromosomal structure, while the section on biochemical genetics gives clear accounts of protein biosynthesis and the expression of gene mutation. Students should find this book informative and stimulating.

\section{ARNOLD SORSBY}

General Cytology. An Introduction to Functional Morphology of the Cell. By Ekkehard Grundmann, translated into English by Dieter M. Kramsch. (Pp. $x+428$; 170 figures. 120s.) London: Arnold. 1966.

It is rare to find a technical book which has nothing to recommend it; this book comes dangerously close to that rarity. In part the blame rests with the publisher for offering a translation which is sometimes incomprehensible. A quaint example occurs on p. 132 where the kinetocentre is described as a structure 'which sometimes shines a little and seems to be the very source of this radiation'; at prophase or thereabouts-the language is a little ambiguous - 'we can well recognize the radiation also on the living object' but by anaphase 'the radiation dims down progressively... I It seems that the author is trying to describe the mitotic spindle and its asters which show lines of protoplasm which 'radiate' from the spindle poles; he is not talking of a source of illumination.
Apart from the poor translation it is not clear why this book was translated at all. There are many books which present the material it covers more accurately, with less bias and with greater lucidity. The dogmatism shown in the text, and the distortion of the published literature on the subject can only prove misleading to the elementary reader and irritating to the more advanced student.

\section{J. Chayen}

Immunological Aspects of Viral Oncolysis. By J. Lindenmann and P. A. Klein. Volume 9 of Recent Results in Cancer Research. (Pp. viii $+84 ; 25$ figures +19 tables. DM 18. U.S. \$4.50.) Berlin, Heidelberg, New York: Springer-Verlag. 1967.

This small volume describes an experimental model for viral oncolysis of transplanted tumour cells. Strain A2G mice, naturally resistant to WSA, a tumouradapted strain of influenza virus, are grafted with an ascites tumour [either Ehrlich, Krebs-2, or Sarcoma 180]. Oncolysis is subsequently induced by WSA infection. Mice surviving oncolysis, and free of tumour, are immune to subsequent challenge with any of these three tumours. The sera of immune mice contain an agglutinin for the tumour cells-and admixture of such sera with tumour cells prevents tumour takes on subsequent inoculation into normal animals-the authors call this passive immunity!

Homogenates of virus-infected tumours will induce immunity in fresh animals, whereas single lysates of tumour cells will not. The authors speculate (pp. 74-5) on the possible application of these discoveries to the therapy of human tumours but suggest that ' ... the following highly hypothetical conditions should be fulfilled: the tumour to be treated should possess vulnerable antigenic targets, and the host should be able to respond to adequate antigenic stimulation'.

R. J. C. HaRris

\title{
The Chicago Conference 1966: Standardization in Human Cytogenetics
}

This Conference was held on the occasion of the Third International Congress of Human Genetics in September 1966 at the University of Chicago to consider the results of and the problems arising from the rapid growth in knowledge of human cytogenetics during the past six years. This has led to difficulties both in the communication of results and the uniform reporting of data.

A Report of this Conference has just been published by the National Foundation-New York, together with reprints of both the Denver and London Conferences and Addenda.

The system of nomenclature proposed by the members of the Chicago Conference should permit greater ease and precision in communicating human karyotype data. Furthermore, the shorthand notation should be readily adaptable to automated data processing and information retrieval systems.

Contributors to this journal are strongly urged to familiarize themselves with this system and to make use of it where practicable. Use however will not be a prerequisite for publications in the fournal of Medical Genetics. Editors may, however, recommend its use where they consider that as a result clarity would be increased.

The Report has been circulated by the National Foundation to all those on its mailing lists, and further reprints of this Report are obtainable free of charge from the Medical Department, The National Foundation-March of Dimes, 800 Second Avenue, New York, N.Y., 10017, U.S.A.

JOHN L. HAMERTON 